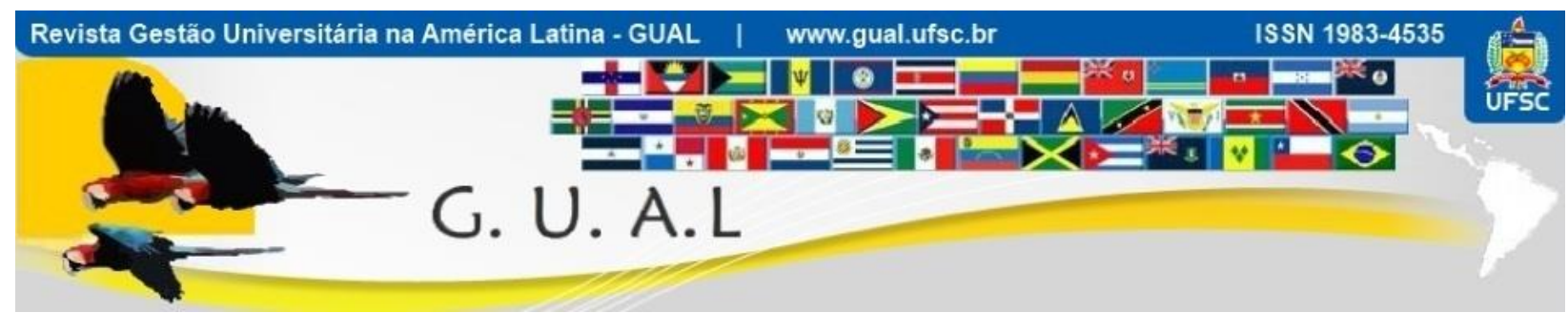

DOI: http://dx.doi.org/10.5007/1983-4535.2014v7n3p43

\title{
O PROCESSO DE GESTÃO DE DESENVOL VIMENTO DO ESPAÇO PÚBLICO NA UNIVERSIDADE: UMA PRÁTICA EDUCATIVA E SOCIAL
}

\section{THE MANAGEMENT PROCESS OF DEVELOPING THE UNIVERSITY PUBLIC SPACE: A EDUCATIONAL AND SOCIAL PRACTICE}

Carla Cristina Dutra Búrigo, Doutora Universidade Federal de Santa Catarina - UFSC carla.burigo@ufsc.br

Cléia Normandina Silveira Ramos, Mestra Universidade Federal de Santa Catarina - UFSC cleia.ramos@ufsc.br

Recebido em 15/abril/2013

Aprovado em 07/agosto/2014

Sistema de Avaliação: Double Blind Review

Esta obra está sob uma Licença Creative Commons Atribuição-Uso. 


\title{
RESUMO
}

O presente artigo tem por objetivo refletir sobre o desenvolvimento do espaço público, na universidade pública federal, como uma prática educativa e social. Este estudo parte dos resultados de pesquisa realizada na Universidade Federal de Santa Catarina (UFSC), sobre a publicização das solenidades de colação de grau, em nível de graduação (RAMOS, 2012). A partir da década de 90, as formaturas da UFSC foram privatizadas sendo, no ano de 2004, resgatado o seu caráter público. A partir dos resultados da pesquisa, foi possível observar fortes evidências de que a formatura pública é envolvida por relações de mediações que refletem diretamente no seu caráter público, democrático e isonômico. Assim, ela se constitui em um processo que se apresenta em constante movimento, contribuindo para a organização ou para a desorganização do espaço público e da identidade da Universidade como instituição social. A Universidade é uma instituição complexa caracterizada pela diversidade da sua comunidade interna e externa. Aliado a isto, as relações que se manifestam no seu fazer diário, diante das políticas públicas educacionais, fazem com que a formatura como uma prática educativa e social, de organização e desenvolvimento do espaço público, demande ações para o fortalecimento da Universidade como instituição social.

Palavras-Chaves: Universidade Pública. Espaço Público. Formatura Pública.

\begin{abstract}
The following article aims to discuss about the public space development in the Federal University, as a social and educative practice. This study starts at the results of a research realized at the Santa Catarina's Federal University (UFSC), about the degree solemnities being realized with public resources (RAMOS, 2012). Beginning in the 90`s, the degrees ceremonies of UFSC were privatized, but in 2004, rescued to it's public assets. From the research results, was possible to see strong evidences that the public degree ceremony is involved by surrounding environment that directly reflects in it's public character, isonomic and democratic. This way, the university constitute itself in a process that is always changing, contributing for de organization or for the disorganization of the public space and the identity of the University as social institution. The University is a complex institution known by its inner and outer community diversity. Allied to that, the relations that manifests in your daily duty, before the educational public politics, makes the degree ceremony as a social and educative practice, of organization and public space development, demands actions to solidify the University as a social institution.
\end{abstract}

Key Words: Public University. Public Space. Public degree ceremony. 


\section{CONSIDERAÇÕES INICIAIS}

O presente artigo tem por objetivo refletir sobre o processo de gestão de desenvolvimento do espaço público, na universidade pública federal, como uma prática educativa e social. Este estudo parte dos resultados de pesquisa realizada na Universidade Federal de Santa Catarina (UFSC), sobre a publicização das solenidades públicas de colação de grau, em nível de graduação (RAMOS, 2012). Para o desenvolvimento deste artigo, a expressão solenidade de colação de grau, será usada como sinônimo de formatura.

Historicamente, as solenidades de colação de grau da Universidade Federal de Santa Catarina, até o fim da década de 80 , apresentavam um caráter público e democrático. A partir da década de 90 foram privatizadas, como reflexo das políticas públicas neoliberais. No ano de 2004, foi resgatado seu caráter institucional, público e democrático, por meio de uma ação institucional. Esta ação que contou com a participação de gestores, professores, alunos e técnico-administrativos em educação vem garantindo a participação na solenidade, de todos os formandos em igualdade de condições e sem custos para o estudante, fortalecendo o caráter público da Universidade, como instituição social.

Entretanto, a formatura pública da UFSC, não se constitui em uma atividade consolidada na perspectiva da garantia do desenvolvimento e preservação do espaço público. Isto porque, as relações que envolvem esta prática requer um esforço no processo da gestão institucional e comprometimento contínuo com o caráter público da solenidade, na sua essência. A formatura pública, que foi resgatada visando à participação em igualdade de condições de todos os formandos, convive diariamente com pressões internas e externas, na perspectiva do atendimento à interesses privados, caminhando assim na contramão dos objetivos do resgate da publicização desta atividade, como uma prática educativa e social.

Isto posto, para a construção do presente artigo, partimos do que tínhamos de mais concreto, ou seja, a nossa concepção de Universidade, como uma prática educativa e social. Após, buscamos refletir sobre a relação de mediação no contexto da Universidade diante da organização e desorganização do espaço público. Depois apresentamos sinteticamente dados da pesquisa de RAMOS (2012) sobre o resgate público das solenidades de colação de grau, em nível de graduação na UFSC. E buscando desvelar novos olhares que esta caminhada pudesse nos propiciar sobre o fenômeno em estudo, em um sentido contrário, retornamos ao objetivo proposto e apontamos algumas considerações finais. 


\section{A UNIVERSIDADE COMO UMA PRÁTICA EDUCATIVA E SOCIAL}

A Universidade, como instituição social, no seu dinamismo diário vive contraditoriamente a necessidade de constituir e desconstituir, de organizar e desorganizar, de fortalecer e enfraquecer o processo de desenvolvimento do espaço público como prática educativa e social. Diante das suas condições de existência, viver a universidade pública é desafiar o lógico, é viver entre a utopia e a realidade cada vez mais estreita e sufocante, entre o elitismo e o antielitismo, entre o que é necessário fazer e o que verdadeiramente se faz no desenvolvimento desta Instituição como uma prática educativa e social (BÚRIGO, 2003).

Ao conceber a Universidade como uma prática educativa e social, estamos situando-a preliminarmente como uma instituição social (CHAUÍ, 2003), ou seja, voltada para a ação social, para a prática social, para o reconhecimento público de sua legitimidade, inseparável da ideia de democracia e socialização, como fruto da conquista da educação e da cultura, como direitos, nos últimos séculos.

A prática social é mediada por relações sociais e não pode estar efetivamente dissociada de uma realidade social concreta, que lhe possibilite condições de realizá-la. Uma das ações que materializa a Universidade como uma prática educativa e social, é o próprio processo da formação, ou seja, a sua essência.

Para tanto, partimos do pressuposto de que a educação é inseparável do processo de formação, como resultado do pensar sobre a realidade. É o resultado da obra do pensamento, da consciência. Este processo deve estar fundamentado em um campo teórico e no contexto histórico, alicerçado em uma proposta pedagógica sólida da interrogação, da reflexão, da crítica, da investigação como uma forma de pensar.

Como adverte MÉSZÁROS (2005, p.76), “[...] a educação não pode funcionar suspensa no ar [...]". Nem mesmo pode ser situada como a única solução das mazelas sociais. Faz-se necessária uma visão crítica social, que se empenhe em explicar e compreender a relação entre a educação e seus condicionantes sociais.

Neste contexto, se situarmos o processo de formação como uma prática social, entenderemos que não é um fenômeno isolado, pois estabelece relações com outros fenômenos que o envolve e com ele interage. Negar a formação como uma prática social é limitar a prática educativa. É negar a essência da Universidade, o que se tem de mais prioritário, ou seja, a formação do homem como opositor e sustentador da sociedade (BÚRIGO, 2009). 
O processo da formação está no fazer diário da Universidade, na sua materialidade, como uma prática educativa e social que a legitima como uma instituição social. Todavia, se esta formação se limitar a atender as demandas do mercado, a essência do neoliberalismo, consequentemente as ações da Universidade terão possibilidades concretas de se refletirem neste contexto.

Para negar esta formação mercadológica, se fazem necessárias condições de existência desta Universidade, que analisem criticamente a prática social e os fatores ideológicos que permeiam esta prática, de forma que se torna fundamental viver, vivenciar, experimentar, adquirir atitudes e valores que é distinto de simplesmente conformar-se com o instituído.

Todavia, há também que se considerar que a Universidade não é um todo homogêneo: há culturas e subculturas que a permeiam. É uma instituição histórica, heterogênea, constituída e constituinte do processo de desenvolvimento da sociedade na qual está inserida.

O movimento histórico da universidade é um componente decisivo no processo histórico da cultura ocidental, pois possibilita compreender uma parte de nossa herança intelectual e de nossa sociedade. A análise da historicidade desta instituição social, permite a reflexão sobre os avanços possíveis, graças ao recuo crítico oferecido pelo olhar do processo histórico que, em cada época, busca preservar o saber passado, integrando-o e adaptando-o às novas concepções que surgem, ou transformando-o.

A universidade foi se constituindo ao longo da história, em um processo de desenvolvimento, como uma manifestação de sustentação e de oposição à ideologia da sociedade, que sempre a teve como um espaço desafiador: como espaço de criação, de expressão de pensamentos livres, que pode desestabilizar o status quo.

Situamos no presente artigo a universidade pública como uma instituição social que "exprime de maneira determinada a estrutura e o modo de funcionamento da sociedade como um todo" (CHAUÍ, 2003, p.1), sendo mantida pela sociedade, legitimada na medida em que responde socialmente com ações que promovam o desenvolvimento dessa mesma sociedade onde está inserida.

Contudo, consideramos interessante destacar que, para que a universidade seja vivenciada como uma instituição social, entre outros aspectos se faz necessário também que os seus gestores tenham a consciência e a responsabilidade de promover ações visando ao fortalecimento do espaço público existente na instituição. 
Todavia, há de se considerar que, para que isso ocorra, é necessário repensar a Universidade como espaço institucional histórico de formação humana, de reflexão crítica, de produção e socialização de conhecimento voltado para a construção da cidadania, numa globalização da vida e da dignidade humana. Globalização da vida, na perspectiva da globalização mais humana, cooperativa, solidária e que atenta aos valores éticos e humanos, reagindo à globalização competitiva, mercadológica que privilegia o espaço privado em detrimento do público.

\section{O ESPAÇO PÚBLICO E O ESPAÇO PRIVADO E SUA RELAÇÃo NA UNIVERSIDADE}

Falar de espaço público é falar de movimento, de organização e desorganização, de fortalecimento e enfraquecimento. É falar de preservação, de acesso democrático, de pluralidade e de ausência de interesses unilaterais. Falar em espaço público em uma universidade federal é falar também em políticas públicas, em políticas educacionais.

Como reflexo das políticas públicas neoliberais que incide sobre as políticas públicas educacionais, além do incentivo à privatização, a partir da década de 90, há uma mudança no foco da formação, que passa a ser voltada para as exigências do mercado. Este processo Dias Sobrinho (2005, p.10) define como mercadorização da educação, ou seja, quando a educação, a formação passam a ser situadas "(...) como produto negociável, regido pelas regras do comércio e atravessado pela concorrência".

A mercadorização da educação, à luz da ideologia neoliberal, converge para as diretrizes do Banco Mundial e da Organização Mundial do Comércio, que repercutiu também sobremaneira na década de 90 , no enfraquecimento do espaço público, e no fortalecimento do espaço privado da universidade pública (BÚRIGO, 2003).

Pesquisas apontam (BÚRIGO, 2009) que a Universidade é legitimadora das ações ideológicas da sociedade e do Estado, pois é uma prática social. Porém, isto não quer dizer que a Universidade seja apática a este contexto. Ela vivencia contraditoriamente a relação de ser legitimadora e opositora, numa relação de identidade como instituição social, principalmente a partir das relações de produção que se estabelecem por meio do processo de formação e do processo de autonomia pedagógico-acadêmica da qual é constitutiva.

A partir da década de 90 a Universidade, diante das políticas públicas de privatização dos seus espaços, vem buscando mecanismos de sobrevivencia, em muitos momentos, distanciando-se de ser um bem público, uma coisa pública, um espaço comum. 
A relação do público e privado é contraditória, ou seja, o que é privado não é público, e vice-versa. Assim, na medida em que o espaço público passa a ser orientado por visões que atendam a interesses particulares, este espaço é descaracterizado e consequentemente deixa de cumprir o seu papel.

Concebemos o espaço público com base em Habermas (1984) e Arendt (1999), como um espaço comum, um mundo comum, visto de vários prismas. Ou seja, um espaço onde diferentes percepções se entrelaçam, no objetivo ao atendimento de uma meta comum, do bem público. Este bem público seria o atendimento da maior gama possível das necessidades da sociedade heterogeneamente constituída por classes sociais.

Este espaço público, não é a ampliação do espaço privado, mas um fórum de debates, um lugar da opinião livre. Não é um espaço da supremacia dos interesses privados, mas um espaço de direitos construídos, de interação dialógica, na busca de objetivos comuns. É um espaço em movimento, que organiza-se e desorganiza-se, diante da interação com a realidade.

Para tanto, se faz necessário que a instituição universidade seja entendida na sua dimensão diante da sociedade e que seu espaço público seja desenvolvido e preservado. Com base em Roio (2008, p.3):

Há que se compreender que a Universidade é apenas um pequeno, mas crucial elemento na vida do País, pois é nessa instância que, em grande medida, se produz conhecimento e se reproduz conhecimento, se qualifica para o trabalho social e para a vida pública. Se não predomina no seio da Universidade a visão de um espaço público e democrático dotado de normas, e voltado para os interesses gerais da humanidade, pouco pode ser feito.

Com o advento do neoliberalismo na década de 90, o que se tem visto é gradativamente a coisa pública sendo apropriada e administrada sob a perspectiva da esfera privada (RAMOS, 2012). Contudo, a separação do que é público e privado está cada vez mais difusa, pois a linha que os divide, é quase invisível. A cultura de apropriação do espaço público é disseminada e fortalecida, muitas vezes, pelos próprios gestores, pelas políticas institucionais que pecam ao não focarem no desenvolvimento e na preservação do espaço público existente na Universidade.

Contudo, há de se destacar a importância dos gestores universitários manterem-se atentos aos movimentos que possam provocar o comprometimento desse espaço público, com a ampliação dos espaços privados dentro da própria instituição, gerando dependência à esfera privada, que, conforme Habermas (1984, p.39), "delimita a sociedade em relação ao poder público". 
O espaço público na universidade federal tem passado por momentos turbulentos. Em alguns períodos parece que é fortalecido, em outros, desorganizado e enfraquecido. Esse movimento de organização e desorganização se dá, em função do contexto em que a Instituição está inserida e de como as políticas públicas influenciam as políticas educacionais; os movimentos sociais; as ações institucionais; a realização do trabalho acadêmico do professor seja no ensino, na pesquisa ou na extensão; e, as atividades laborais exercidas pelos gestores universitários e pelos servidores técnico-administrativos em educação (BÚRIGO, 2003).

Cabe salientar que os gestores públicos universitários, pela essência do cargo público que ocupam, devem promover ações que, além de visarem ao desenvolvimento e à preservação do espaço público, devem contribuir para erradicação, dentro da instituição, da unilateralidade de interesses, principalmente quando nesses interesses estão envolvidos aspectos econômicos e políticos que ampliam a margem que separa as classes sociais.

Consideramos que exemplos como o da UFSC, que democratizou e institucionalizou o processo de colação de grau dos seus cursos de graduação, resgatando o caráter público e acadêmico, contribuem para o desenvolvimento desse espaço público e para a sua preservação. Acreditamos nisso, na medida em que o modelo adotado a partir de 2004 garante a participação, com dignidade, de todos os formandos, em igualdade de condições, independentemente da sua situação socioeconômica.

\section{A COLAÇÃO DE GRAU DOS CURSOS DE GRADUAÇÃO DA UFSC}

A colação de grau é uma atividade obrigatória para que o formando possa obter seu diploma e, consequentemente, possa atuar na sua área de formação. É um ato que está sob a responsabilidade da instituição e que faz parte da vida acadêmica do aluno. Assim, cabe ao aluno cumprir os requisitos exigidos na grade curricular do seu curso e, a Universidade, proporcionar as condições necessárias e dignas para que o aluno receba sua outorga de grau (UFSC, 2011).

De acordo com a legislação interna da UFSC, que regula esta atividade, está clara a intenção da Universidade em praticar a solenidade de colação de grau de maneira democrática, socialmente responsável e, sobretudo, como uma solenidade pública, institucional e acadêmica (RAMOS, 2012). 
Entretanto, sob a influência das políticas públicas neoliberais implementadas no Brasil, a partir da década de 90, o mercado passou a nortear o comportamento da sociedade, e as colações de grau passaram a representar um bom negócio para o setor privado, que se fortaleceu com o aumento do número de empresas especializadas em organização de formaturas.

Paralelamente a esta situação, a universidade pública federal vivenciou o cerceamento financeiro, consequência das políticas públicas educacionais balizadas pelas políticas públicas neoliberais implementadas pelo Governo Federal. Este cerceamento potencializou o desenvolvimento de mecanismos de sustentação da própria Instituição que representaram um olhar menos crítico da Universidade para determinadas atividades, favorecendo a apropriação dos seus espaços públicos.

No caso das formaturas dos cursos de graduação da UFSC, os ritos institucionais passaram a sofrer demérito diante da percepção dos gestores acadêmicos, o que provocou a reprodução, dentro da Instituição, das relações predominantes do mercado e a consequente supressão dos direitos de participação dos formandos em igualdade de condições, das solenidades de colação de grau.

Assim, o mercado apropriou-se da formatura pública da UFSC, desorganizando o espaço público existente e transformando a formatura em uma atividade privada dentro de uma instituição pública, com características excludentes, reduzindo, e muito, seu caráter público e acadêmico. Esta prática limitava a participação na solenidade, apenas aos formandos que pagassem os serviços prestados pelas empresas especializadas do setor (RAMOS, 2012).

Nestes termos, o que passou a acontecer com as formaturas da UFSC, foi um tolhimento do direito democrático de participação do aluno nas solenidades. Bordenave (1994, p.17) argumenta que a participação "não é somente um instrumento para a solução de problemas, mas, sobretudo, uma necessidade fundamental do ser humano". Ao privar o formando de participar da solenidade de colação de grau em uma instituição pública, a Universidade passa a ferir a natureza social do homem de participação, manifestando-se como uma organização qualquer negando o seu papel como uma instituição social.

A prática da formatura privada na UFSC estava sendo realizada, até 2004, sob a lógica do mercado, na qual o fator econômico superava a responsabilidade social da Instituição em 
garantir a isonomia, a democracia e a dignidade dos seus formandos, no processo de colação de grau (RAMOS, 2012).

De acordo com Ramos (2012) o corpo gestor da UFSC, insatisfeito com este cenário, a partir de 2004, desencadeou um processo de resgate da publicização da solenidade pública de colação de grau, visando ao desenvolvimento e preservação do espaço público, que ao longo do tempo veio sendo desfigurado por meio da ação mercadológica que envolveu as solenidades de colação de grau.

As solenidades de colação de grau, a partir de 2004 passaram a ser organizadas e executadas por servidores técnico-administrativos em educação da UFSC, realizadas exclusivamente nas dependências da Universidade e, o mais importante, com garantia de acesso, sem custo e em igualdade de condições para todos os formandos, promovendo a inclusão social dos alunos oriundos das classes sociais menos favorecidas.

A pesquisa realizada por Ramos (2012) foi um estudo de caso de natureza qualitativa, utilizando a análise de documentos, a construção de um arcabouço teórico contextualizando o fenômeno investigado, além de entrevistas semiestruturadas com gestores universitários. A pesquisadora afirma que, ao iniciar o processo de investigação, a percepção que se tinha sobre a formatura pública da UFSC, era de que se constituía em uma atividade consolidada na Instituição.

Entretanto, após ter percorrido todo o processo de investigação, foi possível construir um outro olhar para a prática da formatura pública da UFSC. Aponta que esta prática é envolvida por relações de grandes dimensões e que refletem diretamente no seu caráter público, democrático e isonômico. Assim, Ramos (2012) concebe que a formatura pública da UFSC se constitui em um processo que se apresenta em constante movimento e que pode contribuir para a organização ou para a desorganização do espaço público, de acordo com as circunstâncias que a envolve.

A pesquisa também demonstra que essa mudança no cenário das formtauras da UFSC, promoveu desconfiança e insegurança por partes dos alunos, empresários do setor e de alguns gestores universitários. Porém, dois fatores foram fundamentais para que o processo fosse desencadeado: a determinação e a convicção de alguns gestores de que algo precisaria ser feito, ou seja, a Universidade não poderia mais compactuar com a apropriação desse espaço público pelo setor privado, enfraquecendo-o e desorganizando-o; e a inauguração do Centro 
de Cultura e Eventos (CCEven), com infraestrutura física capaz de comportar eventos de pequeno e médio porte (RAMOS, 2012).

A Universidade, dispondo de um espaço para realizar as solenidades de colação de grau pública, ou seja, o Centro de Cultura e Eventos, e atenta ao movimento privatista que dominava as solenidades de colação de grau, fortalecendo a apropriação do espaço público pelo setor privado, adotou o novo modelo de gestão para as solenidades de colação de grau dos cursos de graduação. A Resolução nº 005/CEG/2004 (UFSC, 2004) da Câmara de Ensino de Graduação, que trata dessa prática acadêmica, estabeleceu normas referentes à organização das solenidades, visando ao resgate da formatura pública na UFSC.

A formatura pública adotada pela UFSC é o resultado do esforço e determinação da Instituição, em enfrentar as dificuldades do contexto gerado a partir da implementação das políticas públicas à luz do neoliberalismo. Diante da legislação vigente, do quadro reduzido de servidores e de recursos financeiros, a implementação desta ação representa acima de tudo, a necessidade de comprometimento por parte da Instituição, ousadia e coragem para "rasgar a camisa de força” (MÉSZÁROS, 2005, p. 03) da lógica do mercado disseminada dentro da própria Instituição, que dominava as regras para a realização das solenidades de colação de grau dos seus cursos de graduação.

Com base na pesquisa realizada por Ramos (2012), o resgate da formatura pública representou um avanço fundamental para a UFSC, como uma instituição social. Este resgate representou o cumprimento de um compromisso social diante da sua comunidade e da própria sociedade. O entendimento de que a solenidade de colação de grau faz parte da vida acadêmica do estudante universitário, e por isso está sob a responsabilidade da Instituição, constitui-se segundo os gestores universitários entrevistados na pesquisa em comento, em um processo de extrema importância tanto para a Universidade, como para os estudantes. Foi uma resposta para a sociedade de que a Universidade retomou aquilo que é público, acadêmico, institucional e que foi apropriado pela iniciativa privada indevidamente.

Promover o tratamento isonômico, democrático e público em atividades inerentes a vida de uma universidade pública, constitui uma esfera do processo da responsabilidade institucional. No entanto, diante das relações que envolvem esta complexa instituição, isso não parece tão simples e óbvio. Muitos fatores envolvem o cumprimento desta responsabilidade, fatores estes que envolvem desde o querer institucional até a implementação de políticas públicas educacionais pelo Governo Federal. 
É consenso, entre os participantes desta pesquisa (RAMOS, 2012), de que um dos fatores que mais influenciam a desorganização dos espaços públicos na universidade pública, é o reflexo das políticas públicas sobre a instituição, especialmente as políticas de financiamento. Materializar o público diante de cerceamento financeiro, como foi vivenciado ao longo da década de 90, não é atribuição fácil. Assim, para a UFSC retomar da iniciativa privada, aquilo que foi apropriado, foi necessário a utilização de mecanismos que sustentasse esta decisão, ou seja, permitisse a conclusão da construção do ambiente onde hoje é o palco das suas formaturas públicas.

Diante disso, acreditamos que a relação entre o público e o privado em uma instituição pública, quando gerenciada à luz do interesse comum, pode representar a possibilidade de a Universidade reverter para a sociedade, os recursos privados envolvidos, na perspectiva do cumprimento do seu compromisso social.

No entanto, a prática da formatura pública não é uma atividade cujo caráter público esteja garantido e consolidado. Em função de tudo o que envolve esta atividade, o que acontece hoje pode não acontecer amanhã, dependendo do contexto em que está inserida. Isto transforma a formatura pública da UFSC em uma atividade que, se a Instituição quiser manter, precisa se conscientizar de que existem inúmeros fatores que possibilitam o enfraquecimento da institucionalização da prática pública, em função da própria representatividade do fenômeno diante da sociedade.

Os resultados da pesquisa (RAMOS, 2012), apontam algumas ações que quiçá possam contribuir para a preservação da formatura pública da UFSC, com vistas à organização e preservação do espaço público inerente a esta atividade:

a) Construção do público a partir da prática coletiva e dialógica: A formatura pública da UFSC é uma atividade que envolve os três segmentos da Universidade, o aluno, o professor e o gestor universitário. É de suma importância que as tomadas de decisão que envolvem esta prática, não se limitem ao entendimento ou aos interesses dos atores sociais que coordenam o processo ou que dirijem a Instituição. Para que a formatura pública seja efetivamente legitimada pela comunidade universitária, gestores universitários e sociedade, se faz necessário que todos sejam envolvidos na construção de um público que realmente atenda os interesses comuns, fortalecido pelo entendimento mútuo de tal forma que todos os 
envolvidos assimilem o comprometimento com o objetivo da formatura pública e toda a complexidade que a envolve;

b) Sustentação, por parte da Instituição, das condições necessárias: Para que a formatura pública da UFSC possa manter seu caráter público, institucional e acadêmico, torna-se necessário que a Instituição mantenha o compromisso de proporcionar as condições necessárias para o desenvolvimento da prática pública das suas formaturas, potencializando assim o fortalecimento e a preservação do seu espaço público. Estas condições passam por comprometimento do direcionamento de investimento tanto no contexto financeiro a partir do orçamento institucional, quanto na capacitação constante dos servidores envolvidos;

c) Política de gestão de pessoal para o exercíco da formatura pública: Uma das dificuldades constatadas na gestão da formatura pública da UFSC, é a manutenção de um corpo de profissionais qualificado para exercer estas atividades. A rotatividade é muito presente e é possível perceber que uma das causas é a especificidade da atividade, principalmente no que se refere aos horários de trabalho. Este aspecto constitui-se em um desafio para a gestão da atividade. Por um lado, a expectativa dos alunos, e seus familiares, é de que as suas formaturas sejam realizadas nos chamados horários nobres, ou seja, à noite, nas sextas-feiras ou durante os sábados. Por outro lado, quem trabalha na organização e realização das formaturas, são servidores públicos da Instituição, cuja carga horária é de 8 (oito) horas diárias. O que é possível perceber é que os servidores que se mantêm no setor, o fazem pelo comprometimento com a atividade e com a Instituição. Outros se sentem em desvantagem em relação aos demais servidores, uma vez que, no horário que a maioria dos servidores se encontra em atividades de lazer, estes estão em plena atividade laboral, gerando descontentamento e consequente desmotivação. Seria muito interessante, para o fortalecimento da atividade, que a Universidade estudasse alternativas institucionais para que o servidor desta área exerça suas atividades, mesmo que em horário diferenciado dos demais, sem se sentir em desvantagem, proporcionando assim, quem sabe, maior motivação, mais 
comprometimento e consequente manutenção do quadro de profissionais atuantes na área;

d) Relação de poder: Outro aspecto que envolve o pessoal que trabalha na organização, é a pressão exercida sobre os mesmos, seja dos alunos, dos seus familiares, dos gestores da Universidade, dos professores ou mesmo da comunidade externa, na tentativa de introduzir mecanismos para o atendimento de interesses privados, promovendo privilégios. É de suma importância que os envolvidos com o processo, dêem sustentação aos preceitos do que seja inerente ao espaço público e suas vertentes, para que os organizadores sejam fortalecidos no exercício das suas atividades; e,

e) Políticas de conscientização: Só é possível conseguir o comprometimento com determinada causa, quando a mesma está muito clara para todos. Só é possível se comprometer com as políticas institucionais implementadas pelos gestores, a partir do momento em que estas políticas são discutidas, analisadas, construídas, compreendidas e assimiladas pela comunidade envolvida. A defesa do espaço público em uma instituição com a complexidade de uma universidade pública, passa pela necessidade de políticas de conscientização em torno da importância do seu desenvolvimento e preservação para as próximas gerações. No momento em que a comunidade tiver consciência da importância do desenvolvimento do espaço público, é possível que o comprometimento com a sua preservação flua com mais naturalidade e as atividades que promovem este desenvolvimento sejam legitimadas e fortalecidas pela própria sociedade. Para tanto, se faz pertinente uma maior divulgação da realização da formatura pública, junto a Instituição, como forma de divulgar e conscientizar sobre a importância da preservação do público, da coisa pública, do espaço público.

A UFSC reassumiu e democratizou a responsabilidade de um serviço que, em função das próprias políticas públicas de racionalização financeira, foi praticamente todo apropriado pela iniciativa privada, a qual, pela cultura sedimentada pelos interesses comerciais, 
estabelecia as regras de inclusão sempre definidas mediante a participação financeira dos estudantes.

De acordo com a pesquisa realizada (RAMOS, 2012), um aspecto importante a ser destacado é o impacto que esta ação gerou diante das empresas de formaturas e mesmo dos formandos. Quanto às empresas, ficou clara a inquietação, preocupação e até indignação dos empresários locais do ramo com a possibilidade de perderem clientes, e consequentemente, diminuírem sua margem de lucro, em função de uma ação da Universidade que, segundo eles, não estava preparada para realizar com bom nível de qualidade e atender às expectativas dos formandos. Quanto aos alunos, além da natural resistência à mudança inerente ao ser humano que teme o novo, a influência das empresas foi implacável ao fortalecer a sua insegurança a respeito do que poderia ocorrer com a solenidade pública realizada sob as novas regras da UFSC.

Assim, os primeiros anos da prática da formatura pública e essencialmente acadêmica, foram marcados por trabalho de conscientização de todos os envolvidos a respeito da real intenção da UFSC, em implantar o novo formato para a realização das solenidades públicas de colação de grau. Um processo de aprendizagem, persistência e mudança cultural que envolveu alunos, professores, gestores e demais servidores técnico-administrativos em educação da Instituição (RAMOS, 2012).

É importante salientar que o resgate da formatura pública pela UFSC, a partir de 2004, é reconhecido por diversas instituições públicas federais e estaduais em todo o território Brasileiro. É comum a solicitação, por parte destas instituições, de orientação sobre a concepção e processo de implementação do mesmo (RAMOS, 2012).

Nestes termos, consideramos que uma das maiores transformações ocorridas com a publicização das formaturas, foi o respeito às diferenças e ao fortalecimento do espaço público, como uma prática educativa e social. Até março de 2012, de acordo com Ramos (2012), foram realizadas quatrocentos e dezoito solenidades públicas de colação de grau para mais de dezoito mil quinhentos e vinte e três formandos, que puderam vivenciar valores correspondentes à democracia, respeito e isonomia, na materialização como uma das ações para o fortalecimento da universidade pública como uma instituição social. 


\section{CONSIDERAÇÕES FINAIS}

Resgatando o objetivo inicialmente proposto, de refletir sobre o desenvolvimento do espaço público, na universidade pública federal, como uma prática educativa e social, com base na pesquisa realizada por Ramos (2012), sobre o processo de publicização das solenidades de colação de grau na Universidade Federal de Santa Catarina, consideramos que a constituição do espaço público se estabelece a partir das relações de mediação que a Universidade mantém com as políticas públicas educacionais, com a sociedade e com o seu papel de identidade como instituição social.

Para tanto, se faz necessário condições concretas para a materialização desta ação, bem como sujeitos atuantes que pensem, vivam e reflitam a Universidade como uma prática educativa e social. Ou seja, sujeitos que concebam a formação como uma prática educativa e social. E neste contexto, a formatura pública é uma ação materializada desta prática, pois foi gestada a partir da concepção da Universidade como uma Instituição Social.

Acreditamos na construção do público a partir do atendimento aos interesses comuns, onde as diferenças são respeitadas, o diálogo é mantido, e os elementos que envolvem a complexidade da universidade pública são compreendidos na perspectiva de promover o desenvolvimento e a preservação destes espaços para as próximas gerações, como uma prática educativa e social.

O público se constitui a partir da negação do privado. Na medida em que o público se abre para os interesses privados, a publicização passa a ser negada. Sem dúvida, o resgate da formatura pública representou um avanço fundamental para a UFSC, como uma instituição social. Este resgate representou o cumprimento de um compromisso social diante da sua comunidade e da própria sociedade. Este resgate materializa a Universidade como uma prática educativa e social, fruto do seu processo de formação.

O entendimento de que a solenidade de colação de grau faz parte da vida acadêmica do estudante universitário, e por isso está sob a responsabilidade da Instituição, constitui-se em um processo de extrema importância tanto para a Universidade, como para os estudantes. Foi uma resposta para a sociedade de que a Universidade retomou aquilo que é público, acadêmico, institucional e que foi indevidamente apropriado pela iniciativa privada.

Promover o tratamento isonômico, democrático e público em atividades inerentes a vida de uma universidade pública, a situa como uma instituição social. Todavia, os resultados da pesquisa (RAMOS, 2012) apontam que, diante das relações que envolvem esta complexa 
Instituição, esta institucionalização é uma ação que necessita ser fortalecida a cada dia, diante de um querer institucional diante das políticas públicas educacionais e da relação com a própria sociedade.

A colação de grau pública em universidade pública, vai muito além do simples ato acadêmico, representa um exercício de cidadania e respeito à democracia. Representa também uma pequena célula que é capaz de contribuir com a organização e o desenvolvimento do espaço público institucional.

Esta prática de resgate da publicização da colação de grau na Universidade Federal de Santa Catarina nos faz pensar que as relações educativas e sociais no fazer da Universidade é possível, desde que possamos ter gestores, servidores docentes e técnico-administrativos em educação em condições de pensar sobre sua realidade, ou seja, que partam da sua realidade, que reflitam sobre ela e que voltem para ela, como sujeitos de suas histórias.

Porém, diante de uma formação generalista, sem fundamentos sólidos reais, que possam vir a sustentar a teoria e a prática, pouco se pode avançar na concepção de sujeitos. A relação da formação, da educação com os demais fenômenos sociais necessita ser desvelada historicamente e analisada criticamente, sustentada pela teoria. Ou seja, a teoria e a prática se inter-relacionam na concepção que toda teoria entra em um vazio social, caso não seja sustentada na prática, e vice-versa.

Isto posto, acreditamos que a formação, como essência da Universidade, a construção do saber, a liberdade acadêmica de poder investigar, de ir ao fundo da questão, de pensar até as raízes das razões, de poder criar e fazer proliferar comunidades interpretativas, são componentes essenciais que levam a situar a Universidade como uma prática educativa e social, na constituição de sua identidade de instituição social, que se revela no público, na coisa pública, de várias opiniões e visões, em busca do bem comum.

\section{REFERENCIAS}

ARENDT, Hannah. A condição humana. Rio de Janeiro: Forense Universitária, 1999.

BORDENAVE, Juan Enrique Diaz. O que é participação. São Paulo: Brasiliense, 1994.

BÚRIGO, Carla Cristina Dutra. O trabalho acadêmico do professor universitário no processo de desenvolvimento do espaço público na universidade federal: um estudo de caso na Universidade Federal de Santa Catarina e na Universidade Federal do Rio Grande do Sul. Programa de Pós-Graduação em Educação da Universidade Federal do Rio Grande do Sul. 2003. Doutorado em Educação. 
A formação de professores de educação básica nos sistemas educacionais da Argentina, do Brasil e do Uruguai. Programa de Pós-Graduação em Educação da Universidade Federal do Rio Grande do Sul. 2009. Pós-Doutorado em Educação.

CHAUÍ, Marilena. A universidade pública sob nova perspectiva. Revista Brasileira de Educação, São Paulo, n.24, p. 5-15, set-dez 2003.

DIAS SOBRINHO, José. Educação superior, globalização e democratização. Qual universidade? 2005. Disponível em: 〈http://www.scielo.br/pdf/rbedu/n28/a14n28.pdf >. Acesso em: 03 jan. 2014.

HABERMAS, Jürgen. Mudança estrutural da esfera pública. Rio de Janeiro:Tempo Brasileiro, 1984.

MÉSZÁROS, István. A educação para além do capital. São Paulo: Boitempo, 2005.

RAMOS, Cléia Normandina Silveira. As solenidades públicas de colação de grau como mecanismo de organização, desenvolvimento e fortalecimento do espaço público: um estudo de caso na Universidade Federal de Santa Catarina. Programa de Pós-Graduação em Gestão Universitária. 2012. Mestrado em Administração Universitária.

ROIO, Marcos Del. A universidade pública e o vírus do privatismo. 2008. Disponível em: <http://www.espacoacademico.com.br/087/87roio.htm>. Acesso em: 03 jan. 2014.

UFSC. Estatuto da Universidade Federal de Santa Catarina. 2011. Disponível em: < http://reitoria.paginas.ufsc.br/files/2011/07/Estatuto_web.pdf>. Acesso em: 03 jan. 2014.

Resolução $\mathbf{N}^{\mathbf{0}}$ 005/CEG/2004. Estabelece as normas referentes à organização das solenidades de colação de grau dos alunos concluintes dos Cursos de Graduação da Universidade Federal de Santa Catarina. 2004. Disponível em: < http://notes.ufsc.br/aplic/RESOCONS.NSF/eab68f213e7101c80325638c005e9041/a2c7dde53 0d7ab1183257153006c3dc2?OpenDocument>. Acesso em: 03 jan. 2014. 